power electric motor. It travels round a track 110 feet in diameter and wears two tracks on the test road. Its maximum speed is 40 miles an hour. Special safety devices have to be incorporated both in the design of the machine and of the building in which it is housed. If it broke away from the centre post when travelling at full speed, it would release energy equivalent to that of a six inch shell. The building containing the machine is roofed so that test roads may be laid in any weather. There are two other machines carrying out similar tests on a smaller scale. In the case of one of these machines the road revolves and drives the wheels, the maximum speed being nine miles per hour. A week's use of one of these machines sometimes represents a year's wear on the ordinary highway. It has been found out that the road generally wears out before the tyre gives way. Physical and chemical tests of roads and road making materials are also carried out at the laboratory. An appliance can bore out a cylindrical core of concrete from a road so that the texture and constituents of the mixture may be examined and its mechanical strength found. Tests on skidding are also made : theoretically, by a small apparatus in the laboratory which finds out the slipperiness of a lubricant, and practically, by means of a special motor cycle and sidecar.

\section{British Empire Cancer Campaign}

Ar the recent quarterly meeting of the Grand Council of the British Empire Cancer Campaign, a communication was received intimating that His Majesty the King had been graciously pleased to become patron of the Campaign. The following grants amounting to $£ 5,530$, and making a total to date of $£ 30,990$ for the year 1936, were approved: $£ 1,100$ to the Radium Beam Therapy Research ; $\mathfrak{1 1 , 7 5 0}$ (in addition to the grant of $\mathfrak{1} 1,850$ already made for the year 1936) to the Mount Vernon Hospital; $£ 500$ (in addition to the grant of $£ 600$ already made for the year 1936) to the Marie Curie Hospital ; $£ 100$ and $£ 80$ to Dr. C. R. Amies, at the Lister Institute and Dr. P. R. Peacock, of Glasgow, respectively, for the

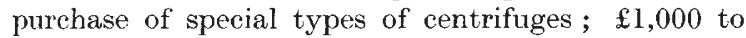
the Manchester Committee on Cancer to cover the cost for two years of investigations to ascertain whether there is any connexion between the use of heary oils in motor-vehicles and the apparent increase in the incidence of cancer of the upper air passages and the lung; $£ 1,000$ to the North of England Branch of the Campaign to meet the cost for the second year of the short-wave investigations being carried out at Newcastle, on behalf of the Campaign, under the direction of Prof. W. E. Curtis and Dr. F. Dickens. In this connexion the Council expressed its appreciation of the technical assistance afforded the workers by the technical staff of the Marconi Company. The Royal Society and the Medical Research Council have nominated Prof. Matthew Stewart, of the University of Leeds, to succeed Prof. R. T. Leiper, who has retired, as one of their five nominees on the Scientific Advisory Committee of the Campaign.

\section{A New Hydraulic Laboratory}

HydRAUlic laboratories are in use for a variety of purposes, including the training of engineers, tests of turbines and pumps, model experiments on ships and seaplane floats and for research on river, reclamation and harbour problems. In the Engineer of April 3, Dr. F. V. A. E. Engel reviews some of the aspects in the design of such laboratories and gives a detailed description of the new hydraulic laboratory at the Park Royal works of Messrs. Electroflo Meters Co. Ltd., erected for the routine work of testing and calibrating meters and for the development and improvement of fluid flow measuring devices. A factor of importance in the design of a meter test plant, he says, is the maintenance of a constant head in the test line. In the plant at the Park Royal works, water is drawn from a sump by two electrically driven centrifugal pumps and delivered to an overhead tank 65 feet above the ground floor. The water then flows through the test line, where Venturi tubes and orifice plates may be installed in a straight pipe $60 \mathrm{ft}$. long. From the test line the water passes into a settling tank and two measuring tanks, and so back to the sump. For timing the tests an interesting device has been adopted which automatically operates the stop watch. When the flow of water entering one measuring tank is switched over to the other, the water jet from the change-over valve interrupts a beam of light impinging on a photo-electric cell, and by means of a thermionic amplifier and relay the stop watch is controlled. In the new laboratory, investigations are in progress on a model of a large Venturi flume recently constructed at the West Middlesex sewerage works at Mogden.

\section{Botanical Acquisitions at the Natural History Museum}

CAPT. F. KINGDON-WARD has presented more than 1,100 specimens collected on his recent expedition to Tibet to the Department of Botany of the British Museum (Natural History). Mr. R. F. Jones has made a collection of plants during the Percy Sladen Expedition to Lake Hula. The lake and its adjacent swamp, an area of about seventeen square miles, was concentrated upon, as the flora will disappear with drainage, and the flora of the hills of Palestine is fairly well known. The collection is of more than four hundred numbers and includes all groups. The investigation was mainly ecological, but the collection contains several new records of flowering plants. Lieut.-Colonel F. M. Bailey, British Envoy Extraordinary and Minister Plenipotentiary at Katmandu, Nepal, has presented 488 flowering plants and 42 vascular cryptogams. These make a useful addition to the valuable Nepalese collections already in tho Department.

\section{Indian Helminths}

G. D. BHALERAO has prepared a list of the helminth parasites hitherto recorded from domesticated animals in India (Imperial Council of Agricultural Research. Scientific Monograph No. 6. Pp. 365. Delhi, 1935. 13s. 3d.). A brief account of the technique of collecting, preserving and preparing the parasites for 